\title{
Dysregulation of the unfolded protein response (UPR) in the dorsolateral prefrontal cortex in elderly patients with schizophrenia
}

\author{
Pitna Kim $\mathbb{1}^{1} \cdot$ Madeline R. Scott $\mathbb{B}^{1} \cdot$ James H. Meador-Woodruff ${ }^{1}$
}

Received: 18 February 2019 / Revised: 10 September 2019 / Accepted: 23 September 2019 / Published online: 2 October 2019

(c) The Author(s), under exclusive licence to Springer Nature Limited 2019

\begin{abstract}
Abnormalities in protein localization, function, and posttranslational modifications are targets of schizophrenia (SCZ) research. As a major contributor to the synthesis, folding, trafficking, and modification of proteins, the endoplasmic reticulum (ER) is well-positioned to sense cellular stress. The unfolded protein response (UPR) is an evolutionarily conserved adaptive reaction to environmental and pathological perturbation in ER function. The UPR is a highly orchestrated and complex cellular response, which is mediated through the ER chaperone protein, BiP, three known ER transmembrane stress sensors, protein kinase RNA-like ER kinase (PERK), activating transcription factor-6 (ATF6), inositol requiring enzyme $1 \alpha(\operatorname{IRE} 1 \alpha)$, and their downstream effectors. In this study, we measured protein expression and phosphorylation states of UPR sensor pathway proteins in the dorsolateral prefrontal cortex (DLPFC) of 22 matched pairs of elderly SCZ and comparison subjects. We observed increased protein expression of BiP, decreased PERK, and decreased phosphorylation of IRE1 $\alpha$. We also observed decreased p-JNK2 and increased sXBP1, downstream targets of the IRE1 $\alpha$ arm of the UPR. The disconnect between decreased p-IRE1 $\alpha$ and increased sXBP1 protein expression led us to measure sXbp1 mRNA. We observed increased expression of the ratio of sXbp1/uXbp1 transcripts, suggesting that splicing of Xbp1 mRNA by IRE1 $\alpha$ is increased and drives upregulation of sXBP1 protein expression. These findings suggest an abnormal pattern of UPR activity in SCZ, with specific dysregulation of the IRE1 $\alpha$ arm. Dysfunction of this system may lead to abnormal responses to cellular stressors and contribute to protein processing abnormalities previously observed in SCZ.
\end{abstract}

\section{Introduction}

The onset of schizophrenia (SCZ) occurs during the neurodevelopmental period between adolescence and adulthood, when important neural connections are formed and strengthened to facilitate cognitive maturation $[1,2]$. These connections use multiple neurotransmitter systems that have been implicated in SCZ [3-5]. The myriad neurotransmitter receptor abnormalities found in SCZ may suggest dysregulation of central pathways critical for modulation of these

Supplementary information The online version of this article (https:// doi.org/10.1038/s41380-019-0537-7) contains supplementary material, which is available to authorized users.

Pitna Kim

pitnakim@uabmc.edu

1 Department of Psychiatry and Behavioral Neurobiology, University of Alabama at Birmingham, Birmingham, AL 35294, USA multiple systems. The endoplasmic reticulum (ER) is a major intracellular organelle that facilitates the synthesis and processing of many proteins [6], including those associated with neurotransmission. The ER has multiple pathways that are responsible for regulating protein quality control and responding to cellular stress. The expression of these pathways is, in part, regulated by the unfolded protein response (UPR), an evolutionarily conserved biochemical pathway that restores cellular homeostatic mechanisms. The UPR is mediated through three known ER transmembrane stress sensors, protein kinase RNA-like ER kinase (PERK), activating transcription factor-6 (ATF6), and inositol requiring enzyme $1 \alpha(\operatorname{IRE} 1 \alpha)$ [7, 8] (Fig. 1). Under normal conditions, ER stress sensors are maintained in an inactive state within the ER membrane through association with the chaperone protein, glucose regulated protein 78 (Grp78), also known as $\mathrm{BiP}$ [9]. In addition to the stress sensors, BiP associates with unfolded and misfolded proteins to facilitate proper protein processing [10-12]. Accumulation of misfolded proteins leads to $\mathrm{BiP}$ dissociation from PERK, IRE1 $\alpha$, and ATF6 [13, 14], which can trigger 


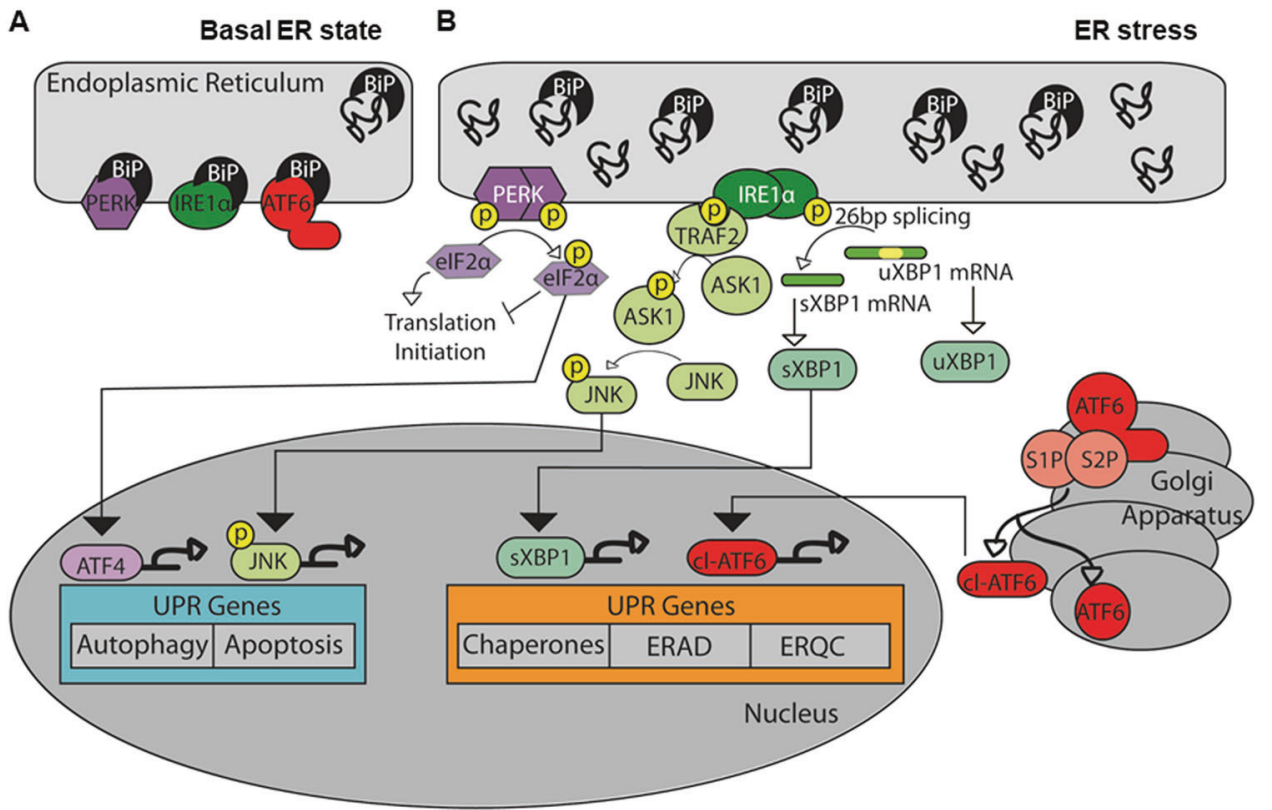

Fig. 1 Signaling pathways from three ER transmembrane stress sensors during unfolded protein response (UPR) in schizophrenia. a ER stress stimulates the activation of the three ER transmembrane stress sensors, protein kinase RNA-like ER kinase (PERK), activating transcription factor-6 (ATF6), and inositol requiring enzyme $1 \alpha$ (IRE1 $\alpha$ ), that are involved in the unfolded protein response (UPR). a Under basal, unstressed conditions, the UPR sensors are present within the ER membrane. The heat shock protein BiP (Grp78) binds these receptors and prevents them from forming homodimers and from translocating out of the cell. b After dissociation of BiP, ATF6 translocates to the Golgi where it is cleaved and trafficked to the nucleus, while PERK and IRE1 $\alpha$ form homodimers and

oligomerization, autophosphorylation, and/or translocation of the UPR sensors, leading to activation of the UPR $[15,16]$. When activated, ATF6 translocates to the Golgi, where it undergoes cleavage and is then targeted to the nucleus [17-19]. In the nucleus, ATF6 acts as a transcription factor to promote UPR target gene expression [20]. PERK and IRE1 $\alpha$ both form homodimers in response to $\mathrm{BiP}$ dissociation [21]. Once these complexes are formed they are able to autophosphorylate themselves. Autophosphorylated PERK phosphorylates eukaryotic translation initiation factor $2 \alpha(\mathrm{eIF} 2 \alpha)$ [21]. Phosphorylated eIF $2 \alpha$ is no longer able to associate with the translation initiation complex, leading to decreased global protein synthesis and increased expression of activating transcription factor 4 (ATF4) [21]. ATF4 promotes expression of proteins associated with autophagy and apoptosis [22]. Autophosphorylated IRE1 $\alpha$ has both kinase and RNAse activity, and a major downstream effect of IRE1 $\alpha$ activity is unconventional mRNA splicing of the transcription factor $\mathrm{x}$-box binding protein 1 (XBP1) [23, 24]. The spliced form of autophosphorylate. Activation of the PERK pathway leads to phosphorylation of eukaryotic translation initiation factor $2 \alpha$ (eIF2 $\alpha$ ) and increased expression of activating transcription factor 4 (ATF4), while activation of the IRE1 $\alpha$ pathway leads to unconventional mRNA splicing of the transcription factor $\mathrm{x}$-box binding protein 1 (XBP1). In addition, IRE1 $\alpha$ activation recruits TNF receptor associated factor 2 (TRAF2) and results in phosphorylation of apoptosis signal-regulating kinase 1 (ASK1), which then phosphorylates the transcription factor cJun N-terminal kinase (JNK). ATF6, ATF4, and spliced XBP1 (SXBP1) function as transcription factors of UPR target genes, such as ER chaperones, the ER quality control system (ERQC) and ER-associated degradation (ERAD)

$\mathrm{XBP} 1$ (sXBP1) acts as a transcription factor and regulates expression of lipid biosynthetic enzymes, proteins responsible for ER quality control (ERQC), and ER associated degradation (ERAD) $[25,26]$.

The UPR is known to regulate cell differentiation, survival, and death $[6,27,28]$. While activation of the UPR is traditionally associated with increased cellular stress and misfolded proteins, constitutive activity of the UPR is also required in cells with a high secretory load, such as neurons $[27,29]$. This leads to increased sensitivity of the brain to abnormalities in the UPR. This is reflected in studies that implicate the UPR in neurodegenerative diseases including Alzheimer's Disease [30], Parkinson's Disease [31], amyotrophic lateral sclerosis [32], Huntington's Disease [33, 34], and Creutzfeldt Jacob Disease [35], as well as in psychiatric disorders including bipolar disorder, major depressive disorder, and SCZ [36-39].

Previous reports demonstrating abnormal N-linked glycosylation, subcellular localization, and expression of receptor associated-proteins of both glutamatergic and 
GABAergic systems in SCZ brain [40-45] are consistent with abnormal protein processing and subcellular targeting of neurotransmitter receptors. We propose that a potential mechanism that reconciles these findings in SCZ is abnormal synthesis and handling of receptor proteins in the ER. Previous work from our lab has demonstrated abnormalities in various ER-related pathways, including ERAD and glycophosphatidylinositol-associated protein quality control, supporting a role for the ER in SCZ pathophysiology [46, 47]. The central role of the UPR in regulating protein processing led us to hypothesize that abnormalities of the UPR may be associated with ER abnormalities in SCZ brain. To test this, we measured expression of UPR sensors and associated proteins to further define UPR expression and regulation in the dorsolateral prefrontal cortex (DLPFC) in SCZ and matched comparison subjects.

\section{Materials and methods}

\section{Human subjects}

Samples of dorsolateral prefrontal cortex were obtained from the Mount Sinai/Bronx Veterans Administration Medical Center Department of Psychiatry Brain Collection. Assessment, consent, and postmortem procedures were conducted as required by the Institutional Review Boards of Pilgrim Psychiatric Center [48, 49], Mount Sinai School of Medicine and the Bronx Veterans Administration Medical Center. A total of 22 subjects diagnosed with SCZ based on DSM-III-R criteria were pairwise matched with comparison subjects by sex, age, tissue $\mathrm{pH}$, and postmortem interval (PMI) (Supplementary Table S1). Brains from subjects were removed at autopsy and sliced into $0.8-1 \mathrm{~cm}$ slabs in the coronal plane. Full thickness of gray matter from the cortex was blocked into $1 \mathrm{~cm}^{3}$ cubes and stored at $-80^{\circ} \mathrm{C}$ until use $[48,49]$.

\section{Antipsychotic treated rats}

Male Sprague-Dawley rats were housed in pairs and treated with chronic administration of either $28.5 \mathrm{mg} / \mathrm{kg}$ haloperidol decanoate (HAL; $N=10)$ or vehicle (VEH; $N=10$ ) delivered once every 3 weeks for 9 months via intramuscular injection, for a total of 12 injections. This method of drug delivery, length of treatment, and dose has been previously described [50-52]. Animals were euthanized by rapid decapitation following $\mathrm{CO}_{2}$ administration, frontal cortexes were dissected on ice, then snap frozen and stored at $-80{ }^{\circ} \mathrm{C}$ until use. The Institutional Animal Care and Use Committee of the University of Alabama at Birmingham approved all procedures using these animals.

\section{Protein expression studies}

\section{Tissue preparation}

For protein expression studies, tissue samples from each subjects were homogenated on ice in $5 \mathrm{mM}$ Tris- $\mathrm{HCl} \mathrm{pH}$ $7.5,0.32 \mathrm{mM}$ sucrose with a protease inhibitor tablet and a phosphatase inhibitor tablet (Complete Mini, EDTA-free and PhosSTOP, both from Roche Diagnostics, Mannheim, Germany) using a glass tissue grinder. Protein concentration was determined using a BCA protein assay kit (Thermo Scientific, Rockford, Illinois). After homogenization, samples were stored at $-80{ }^{\circ} \mathrm{C}$ until use.

\section{Western immunoblotting}

Samples for western blot analyses were prepared with MilliQ water and sample buffer (6X solution: $4.5 \%$ sodium dodecyl sulfate (SDS), $1.5 \% \quad \beta$-mercaptoethanol, $0.018 \%$ bromophenol blue, and $36 \%$ glycerol in $170 \mathrm{mM}$ Tris- $\mathrm{HCl}$, $\mathrm{pH}$ 6.8) and heated at $70^{\circ} \mathrm{C}$ for $10 \mathrm{~min}$. Samples were then loaded on $4-12 \%$ Bis-Tris gels (Invitrogen), subjected to SDS-polyacrylamide gel electrophoresis, and transferred to nitrocellulose membranes using standard semi-dry transfer methods. To reduce nonspecific binding, blots were incubated in either 50\% Odyssey Blocking buffer (Li-Cor) in Tris-buffered saline (TBS) or 5\% bovine serum albumin in TBS for $1 \mathrm{~h}$ at room temperature (RT) prior to primary antibody incubation. Conditions for probing were optimized to be within the linear range of detection for each primary antibody (Supplementary Table S2). Antibodies were stored and handled according to the manufacturer's instructions. The specificity of commercially available antibodies was evaluated by western blotting. Validation of the specificity of commercially available antibodies that were studied are given in Supplementary Fig. F1.TBS $+0.1 \%$ Tween-20 was used for wash steps before and after a $1 \mathrm{~h}$ incubation at RT with the appropriate secondary antibody, and membranes rinsed with Milli-Q water prior to scanning. Membranes were scanned using a LiCor Odyssey scanner at a resolution of $169 \mu \mathrm{m}$ and an intensity level of five.

\section{Xbp1 mRNA analysis}

\section{Total RNA isolation}

RNA was isolated using a RNeasy Mini Kit (cat\# 74106 Applied Qiagen ${ }^{\circ}$ ). For each subject, RNA concentration was determined by spectrophotometry (ND1000, Thermo Fischer Scientific, Inc.) at $260 \mathrm{~nm}$ and equal amounts of RNA were used to synthesize cDNA using a high capacity cDNA Reverse Transcription Kit (cat\# 4368813, Applied Biosystems ${ }^{\circ}$ ). RIN values of all samples were determined. 
Over $80 \%$ of samples had RINs $\geq 6$, an integrity value previous reported suitable for RT-qPCR studies in brain tissue [53].

\section{Electrophoretic analysis of Xbp1 mRNA splicing}

PCR was performed with Platinum ${ }^{\mathrm{TM}}$ Green Hot Start PCR Master Mix (cat\#13001012, Thermo Fischer Scientific, Inc), according to the manufacturer's recommendations. In brief, $1 \mu \mathrm{M}$ of each primer was mixed with $12.5 \mu \mathrm{M}$ of Platinum $^{\mathrm{TM}}$ Green Hot Start PCR Master Mix, $5 \mu$ of Platinum GC Enhancer and $5 \mu \mathrm{l}$ of cDNA. To prepare samples for analysis of sXbp1 mRNA, we treated the samples with PstI. Under unmodified conditions, the amount of uXbp1 is much greater than Xbp1. The section removed by IRE1 $\alpha$ mediated splicing is $26 \mathrm{bp}$, a small enough difference that the excess of uXbp1 masks detection of the spliced form. Therefore, we used PstI, a restriction endonuclease that cleaves Xbp1 at a site only contained within the unspliced form, to specifically digest uXbp1 and unmask sXbp1. Samples $(25 \mu \mathrm{l})$ were incubated with PstI $(1 \mu \mathrm{l})$ overnight at $37^{\circ} \mathrm{C}$, followed by preamplification of $\mathrm{Xbp} 1$ transcript products using Xbp1 primer sets (forward: 5'-TTACGAGA GAAAACTCATGG-3' /reverse: 5'-TCTACCCAGAAGG ACCCAGT-3'). Samples were then resolved on $2 \%$ agarose gels containing ethidium bromide at $60 \mathrm{mV}$ for $1.5 \mathrm{hr}$ before visualizing by UV light. Images were collected with Gel Doc ${ }^{\mathrm{TM}}$ XR + Gel Documentation System (Bio-Rad Laboratories, USA) and the identity of the PCR products obtained with the Xbp1 primers was verified by DNA sequencing.

\section{Data and statistical analysis}

Image Studio Lite Version 4.0.21 (LiCor, Lincoln, NE, USA) was used to determine integrated intensity values from both western blots and agarose gels. All samples were run in duplicate, and after intralane normalization these values were averaged. For proteins, integrated intensity values were normalized to intralane values of Valosin Containing Protein, which has been reported to not be differentially expressed in SCZ brain [54]. Expression of phosphorylated forms of proteins was normalized to the expression of their total forms. The relative amount of Xbp1 mRNA splicing was defined as the ratio of sXbp1 to uXbp1 mRNA levels. Given that many dependent variables were not normally distributed, primary analyses were performed the nonparametric Wilcoxon matched-pairs signed rank test. To determine the effect of potential covariates, Pearson or Spearman rank correlations between protein expression and subject age, tissue $\mathrm{pH}$, and PMI were performed for all dependent measures. Prior to these correlation analyses, D'Agostino
\& Pearson omnibus normality tests were performed to determine if data were normally distributed. If a significant Pearson correlation was observed, an ANCOVA was then used to determine the effect of diagnosis when accounting for the relevant covariates. Alternatively, if a significant Spearman correlation was observed, a nonparametric ANCOVA using the Quade method was performed. All statistical analyses were performed in GraphPad Prism 6 (La Jolla, CA, USA) or STATISTICA version 7 (StatSoft, Inc, Tulsa, OK, USA) with $\alpha=0.05$.

\section{Results}

\section{UPR sensor expression and activation is abnormal in schizophrenia}

We measured expression of $\mathrm{BiP}$, the three UPR stress sensors, PERK, IRE1 $\alpha$, and ATF6, and their corresponding activated states, p-PERK, p-IRE1 $\alpha$, and cl-ATF6. We observed increased in SCZ BiP expression $(W=235, p<$ 0.0001), decreased PERK expression $(W=-195, p=$ 0.0008 ), and no change in IRE1 $\alpha$ or ATF6 expression (Fig. 2, Table 1). In addition, p-IRE1 $\alpha$ expression ( $W=$ $-139, p=0.0229)$ was decreased, while p-PERK and clATF6 were unchanged (Fig. 2, Table 1). Analysis of covariates demonstrated a positive correlation between PERK expression and age $(r=0.40, p=0.007)$, and a follow-up ANCOVA indicated that when controlling for age, there is no longer a significant effect of diagnosis, suggesting that changes in PERK expression between the subject groups are driven by differences in age rather than illness. In addition, no difference in expression of BiP, PERK, or p-IRE1 $\alpha$ was observed in rats treated with haloperidol (Fig. 2).

\section{Expression and activation of UPR effectors suggests abnormal activation of the IRE1a pathway}

In addition to the UPR sensors, we measured expression and activation of UPR downstream effectors. From the PERK pathway, we measured expression of eIF $2 \alpha$, p-eIF $2 \alpha$, and ATF4, and found no differences between comparison and SCZ subjects. In the IRE1 $\alpha$ pathway, we measured expression of both the spliced and unspliced forms of XBP1, TRAF2, and both the expression and phosphorylation of ASK1, JNK1, and JNK2. We found a decrease in SCZ of both SXBP1 $(W=173, p=0.004)$ and the ratio of sXBP1/uXBP1 $(W=143, p=0.02)$. Additionally, both phosphorylation of JNK2 (W=-165, $p=0.006)$ and the ratio of $\mathrm{p}-\mathrm{JNK} 2 / \mathrm{JNK} 2(W=-177, p=0.003)$ was decreased in SCZ (Fig. 3, Table 1). No changes in uXBP1, TRAF2, ASK1, or JNK1 expression were observed, nor was there abnormal phosphorylation of ASK1 or JNK1. 


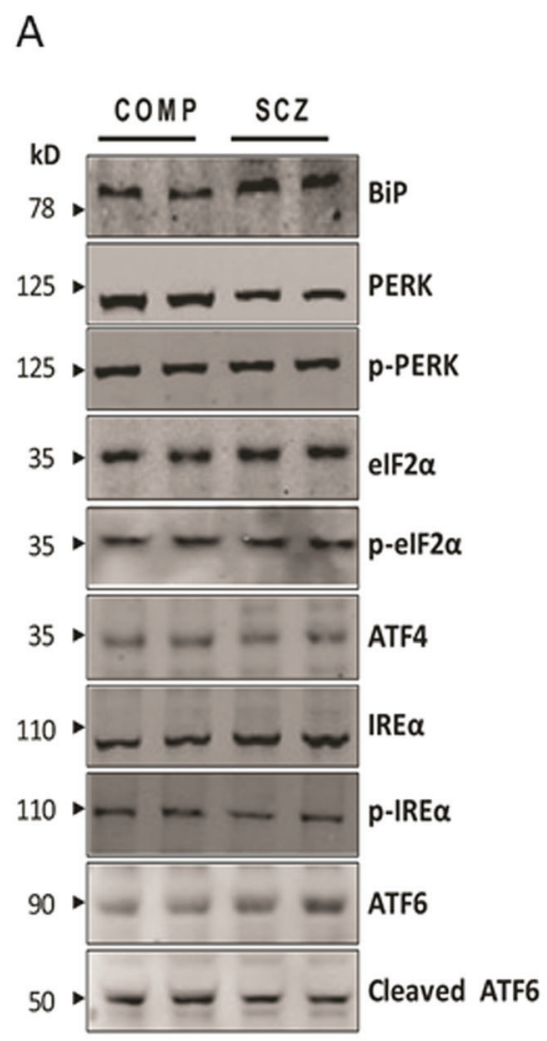

B
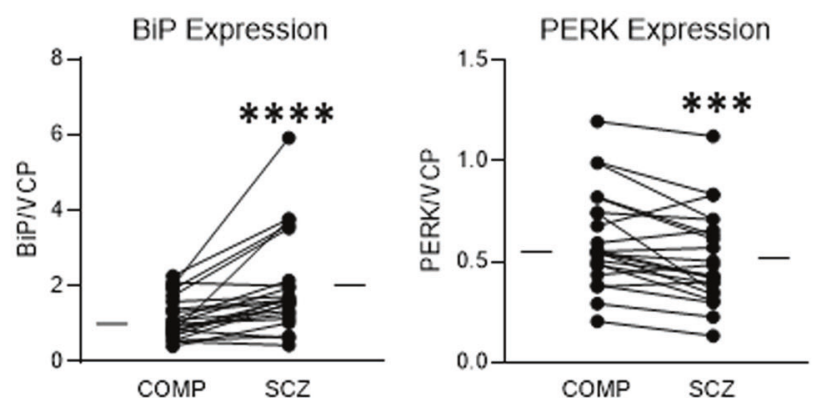

IRE1a Phosphorylation

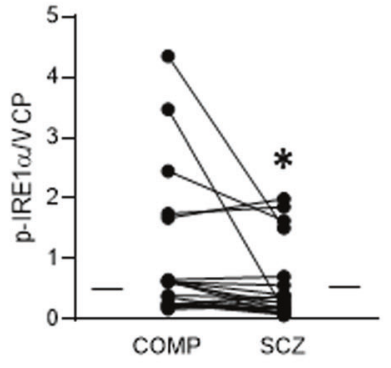

C
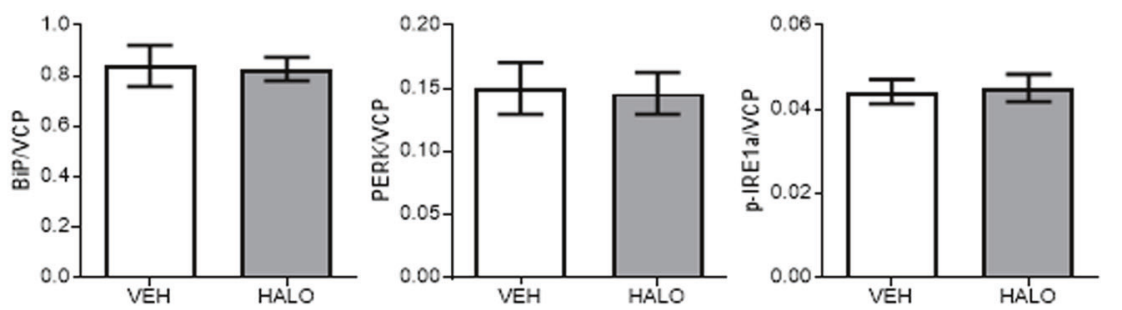

Fig. 2 Altered expression level of UPR signaling pathway- related ER transmembrane stress sensor proteins in schizophrenia. Protein expression of UPR signaling pathway-related proteins was measured in paired schizophrenia (SCZ) and comparison (COMP) subjects. a Representative western blots are shown for paired comparison and schizophrenia subjects. b Increased expression was observed for BiP, and decreased expression was observed for PERK, and p-IRE1 $\alpha$,

None of these dependent measures were significantly correlated with age, $\mathrm{pH}$, or PMI, and were not different between rats treated with vehicle or haloperidol (Fig. 3).

\section{Xbp1 mRNA splicing is increased in schizophrenia}

We found decreased p-IRE1 $\alpha$ and increased SXBP1 protein expression. Activation of IRE1 $\alpha$ leads to an unconventional posttranscriptional splicing of $\mathrm{uXbp} 1 \mathrm{mRNA}$ to produce a spliced form of sXbp1 mRNA that is translated as sXBP1 protein $[55,56]$. To determine at what stage the disconnect between IRE1 $\alpha$ activation, as measured by $p$-IRE1 $\alpha$ expression, and XBP1 splicing, as measured by sXBP1 protein expression, occurs, we measured mRNA expression of different forms of Xbp1. Similar to protein expression, we found increased expression of sXbp1/uXbp1 mRNA $(W=169, p=0.005)$ in SCZ (Fig. 4, Table 1). though the ratio of $\mathrm{p}$-IRE1 $\alpha$ to total IRE1 $\alpha$ was not significantly different. $\mathbf{c}$ BiP, PERK, p-IRE1 $\alpha$, and the ratio of p-IRE1 $\alpha$ to total IRE1 $\alpha$ expression were not significantly different between rats that had received chronic haloperidol (HAL) treatment and those that were vehicle treated $(\mathrm{VEH})$. Data are expressed as means \pm SEM. ${ }^{*} p<0.05$, $* * * p<0.001, * * * * p<0.0001$

\section{Discussion}

In this study, we investigated the UPR through protein and activity-marker expression levels in the DLPFC in SCZ. Of the initial stress sensors of the UPR, we observed increased expression of BiP, decreased expression of PERK, and decreased phosphorylated IRE1 $\alpha$. We also measured downstream effectors of both the PERK and IRE1 $\alpha$ arms of the UPR. While no change in PERK substrates was found, we observed decreased p-JNK2 and increased sXBP1, downstream targets of the IRE1 $\alpha$ arm of the UPR. The disconnect between p-IRE1 $\alpha$, a marker of IRE1 $\alpha$ activation, and $\mathrm{SXBP} 1$ protein expression was surprising and led us to measure sXbp1 mRNA directly. We observed increased expression of the ratio of $\mathrm{sXbp} 1 / \mathrm{uXbp} 1$, suggesting that splicing of Xbp $1 \mathrm{mRNA}$ by IRE1 $\alpha$ itself has increased and drives upregulation of $\mathrm{sXBP1}$ protein expression rather than 
Table 1 Quantification of differentially expressed proteins of ER transmembrane stress sensors in schizophrenia and comparison subjects

\begin{tabular}{|c|c|c|c|c|}
\hline Target protein & Comparison & Schizophrenia & $W$ value & $p$-value \\
\hline $\mathrm{BiP}$ & $1.01(0.75-1.63)$ & $1.65(1.23-5.92)$ & 235 & $<0.0001$ \\
\hline \multicolumn{5}{|l|}{ ATF6 pathway } \\
\hline ATF6 & $0.35(0.23-0.80)$ & $0.42(0.21-0.77)$ & 19 & \\
\hline cl-ATF6 & $0.37(0.21-0.45)$ & $0.29(0.18-0.48)$ & -29 & \\
\hline cl-ATF6/ATF6 & $0.75(0.61-1.01)$ & $0.70(0.59-0.78)$ & -109 & \\
\hline \multicolumn{5}{|l|}{ PERK pathway } \\
\hline PERK & $0.55(0.47-0.77)$ & $0.46(0.35-0.67)$ & -195 & 0.0008 \\
\hline p-PERK & $0.69(0.44-1.28)$ & $0.88(0.41-1.43)$ & -25 & \\
\hline p-PERK/PERK & $1.35(0.78-2.84)$ & $2.06(0.65-3.35)$ & 95 & \\
\hline $\mathrm{eIF} 2 \alpha$ & $0.22(0.07-0.57)$ & $0.20(0.07-1.31)$ & 57 & \\
\hline p-eIF $2 \alpha$ & $2.07(0.94-8.53)$ & $1.75(0.97-8.45)$ & 39 & \\
\hline p-eIF $2 \alpha /$ eIF $2 \alpha$ & $14.45(9.30-20.75)$ & $11.17(9.11-20.12)$ & 1 & \\
\hline ATF4 & $0.047(0.030-0.064)$ & $0.052(0.040-0.077)$ & 45 & \\
\hline \multicolumn{5}{|l|}{ IRE1 $\alpha$ pathway } \\
\hline $\operatorname{IRE} 1 \alpha$ & $1.35(0.87-4.86)$ & $1.16(0.98-4.17)$ & -25 & \\
\hline p- IRE1 $\alpha$ & $0.50(0.25-0.91)$ & $0.28(0.14-0.60)$ & -139 & 0.0229 \\
\hline p- IRE $1 \alpha / \operatorname{IRE} 1 \alpha$ & $0.34(0.19-0.89)$ & $0.20(0.09-0.43)$ & -77 & \\
\hline \multicolumn{5}{|l|}{ IRE1 $\alpha-\mathrm{XBP} 1$ pathway } \\
\hline $\mathrm{uXBP1}$ & $0.014(0.008-0.215)$ & $0.013(0.008-0.211)$ & -55 & \\
\hline sXBP1 & $0.020(0.017-0.035)$ & $0.033(0.020-0.045)$ & 173 & 0.0037 \\
\hline sXBP1/uXBP1 protein & $1.62(1.25-2.38)$ & $2.01(1.58-2.59)$ & 143 & 0.0190 \\
\hline sXBP1/uXBP1 mRNA & $0.20(0.14-0.34)$ & $0.28(0.17-0.62)$ & 169 & 0.0047 \\
\hline \multicolumn{5}{|l|}{ IRE $1 \alpha$-JNK pathway } \\
\hline ASK1 & $0.28(0.15-0.45)$ & $0.42(0.19-0.65)$ & 29 & \\
\hline p-ASK1 & $0.58(0.37-0.89)$ & $0.44(0.36-0.70)$ & -109 & \\
\hline p-ASK1/ASK1 & $1.93(1.05-3.11)$ & $1.23(0.95-2.77)$ & -65 & \\
\hline JNK1 & $0.045(0.035-0.078)$ & $0.052(0.033-0.069)$ & -61 & \\
\hline p-JNK1 & $0.13(0.07-0.21)$ & $0.10(0.08-0.13)$ & -109 & \\
\hline p-JNK1/JNK1 & $2.35(1.80-3.04)$ & $2.06(1.74-2.89)$ & -69 & \\
\hline JNK2 & $0.064(0.030-0.084)$ & $0.069(0.034-0.102)$ & 65 & \\
\hline p-JNK2 & $0.13(0.10-0.20)$ & $0.11(0.08-0.14)$ & -165 & 0.0059 \\
\hline p-JNK2/JNK2 & $2.40(1.83-3.27)$ & $2.07(1.29-2.55)$ & -177 & 0.0029 \\
\hline
\end{tabular}

Data are reported as median (IQR). Data were analyzed using a Wilcoxon matched pairs signed rank test, $n_{\text {pair }}=22$. a change in SXBP1 degradation or translation. These findings suggest abnormal expression and regulation of the UPR and its downstream targets in SCZ.

These findings support a growing body of evidence for a fundamental deficit in ER protein processing pathways. Increased protein expression of $\mathrm{BiP}$, phosphorylation of IRE1 $\alpha$ and PERK, and cleavage of ATF6 are commonly used markers of UPR activity [57]. BiP is a molecular chaperone highly enriched in the ER, and has been found to be dysregulated in several proteomic studies in SCZ [58-61]. Within the lumen of the ER, BiP primarily interacts with unfolded substrates and protein folding machinery, and appears to have an active role in facilitating protein folding [62]. Cellular stress can lead to increased $\mathrm{BiP}$ expression, and increased expression of $\mathrm{BiP}$ protein has become a marker for ER stress [11, 15, 57, 63]. In this study, we observed increased $\mathrm{BiP}$ expression, suggesting a role for cellular stress in SCZ. This is consistent with previous reports that have demonstrated markers of increased oxidative stress, such as increased lipid peroxidation, reactive oxygen species (ROS), and decreased antioxidant levels in postmortem brain in SCZ [64-67].

In contrast to upregulation of $\mathrm{BiP}$, we also observed decreased phosphorylation of IRE1 $\alpha$ in SCZ. Of the three sensor arms, the IRE1 $\alpha$ pathway is the most evolutionarily conserved signaling branch $[24,68]$. IRE1 $\alpha$ has both serine/ threonine kinase and endoribonuclease (RNase) activities, which are activated upon dissociation of BiP and subsequent 
A

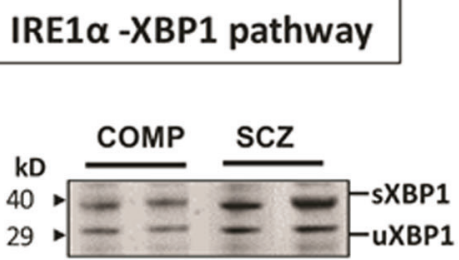

B

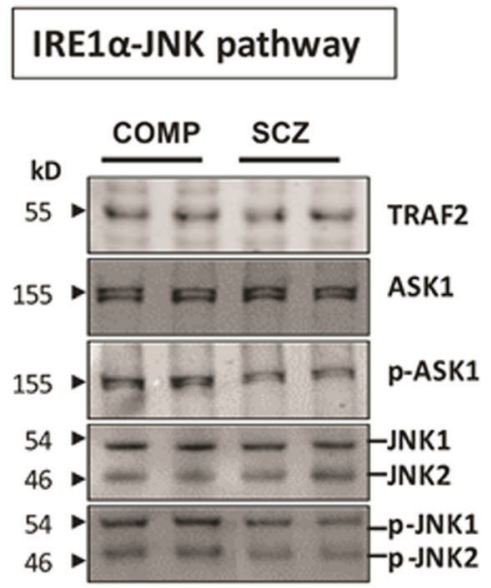

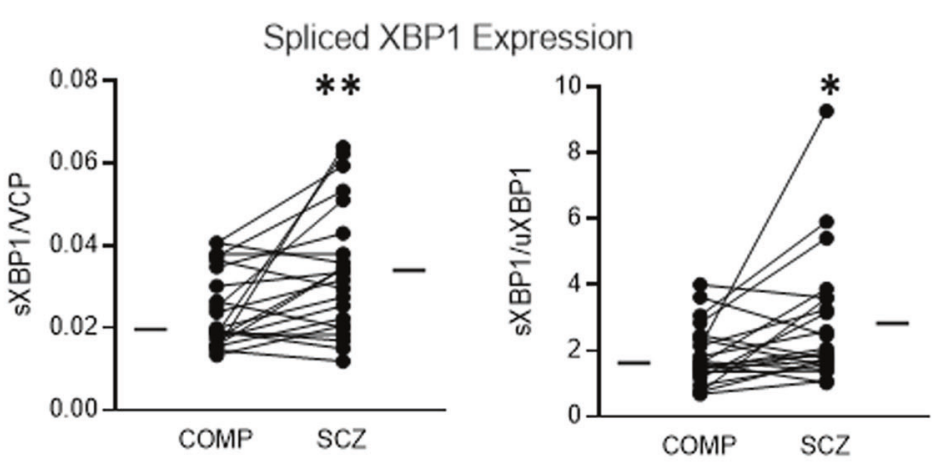

JNK2 Phosphorylation
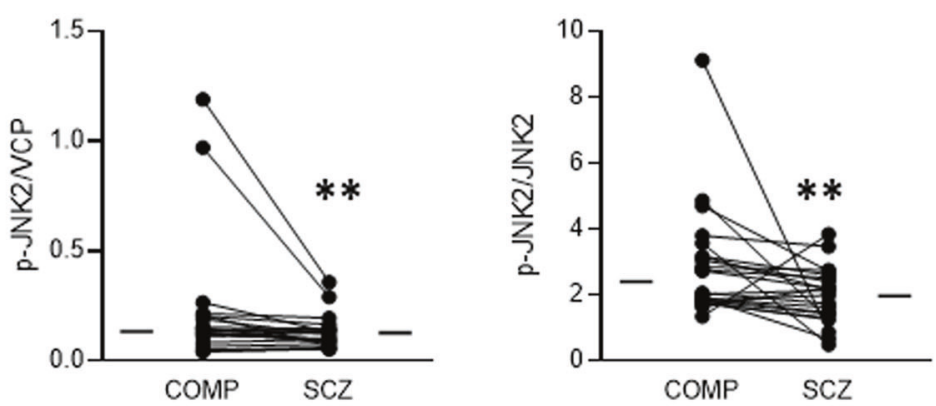

C
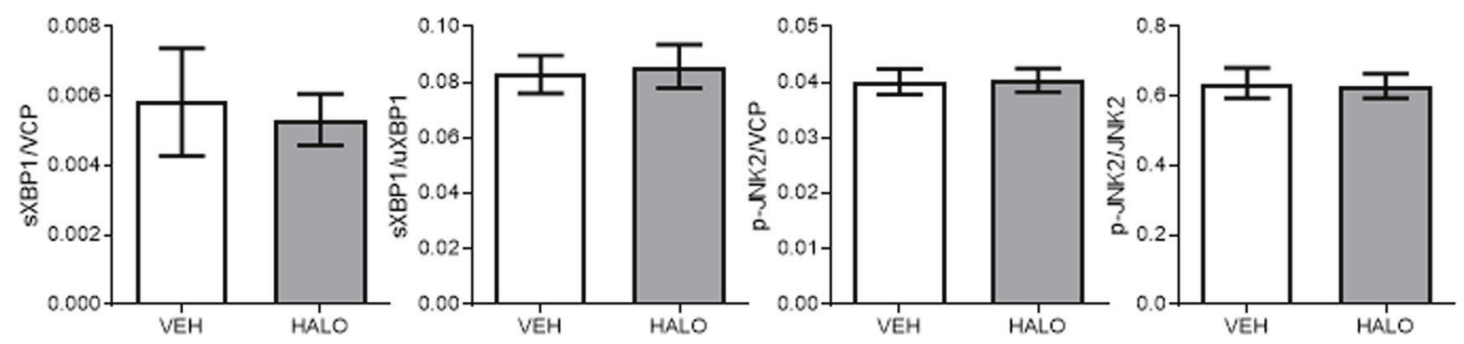

Fig. 3 IRE1 $\alpha$ downstream effectors are abnormally expressed and phosphorylated in schizophrenia. Protein expression and phosphorylation of proteins downstream of $\mathrm{p}$-IRE1 $\alpha$ signaling was measured in paired schizophrenia (SCZ) and comparison (COMP) subjects. a p-IRE1 $\alpha$ leads to splicing of Xbp1 mRNA and synthesis of the spliced form of XBP1 protein (sXBP1). Representative western blots of sXBP1 and unspliced XBP1 (uXBP1) are shown; /both sXBP1 expression and the ratio of $\mathrm{SXBP} / \mathrm{uXBP} 1$ are increased in SCZ. b p-IRE $1 \alpha$ also has kinase activity that leads to phosphorylation of

protein in the ASK1/JNK signaling cascade. Representative western blots of proteins associated with p-IRE1 $\alpha$ kinase activity are shown; both phosphorylation of JNK2 (p-JNK2) and the ratio of p-JNK2/ JNK2 are decreased in SCZ. c p-JNK2, sXBP1, and the ratios found changed in SCZ were not significantly different in rats that had received chronic haloperidol (HAL) treatment when compared with vehicle treated animals $(\mathrm{VEH})$. Data are expressed as means \pm SEM. $* p<0.05, * * p<0.01$

dimerization of and autophosphorylation in response to ER stress [6, 27, 28, 69]. Phosphorylation of IRE1 $\alpha$ attracts TRAF2, which in turn promotes association of ASK1 [70]. The formation of this complex allows for IRE1 $\alpha$ to phosphorylate ASK1, which then phosphorylates JNK $[6,27,28,69]$. JNK is known to have three distinct isoforms, JNK1, JNK2, and JNK3, and JNK1/2 both upregulate proteins associated with apoptosis $[6,27,28,69]$. Consistent with reduced p-IRE1 $\alpha$, phosphorylation of JNK2 was also decreased in SCZ. P-ASK1 was not significantly decreased. Decreased p-IRE1 $\alpha$ and p-JNK2 suggests that the
IRE1 $\alpha$-ASK1-JNK signaling pathway is downregulated, and that apoptotic processes may be attenuated in SCZ. This would be consistent with and may provide a mechanistic explanation for previous observations that there is no evidence of increased cell death despite dysregulation of cellular homeostasis in the brain in SCZ [71, 72]. Phosphorylation of JNK has also been observed in the ACC of SCZ subjects [73], supporting a more widespread role for JNK signaling downregulation in this illness.

A unique target of IRE1 $\alpha$ RNase activity is Xbp1 mRNA, from which IRE1 $\alpha$ removes a 26-nucleotide intron, 


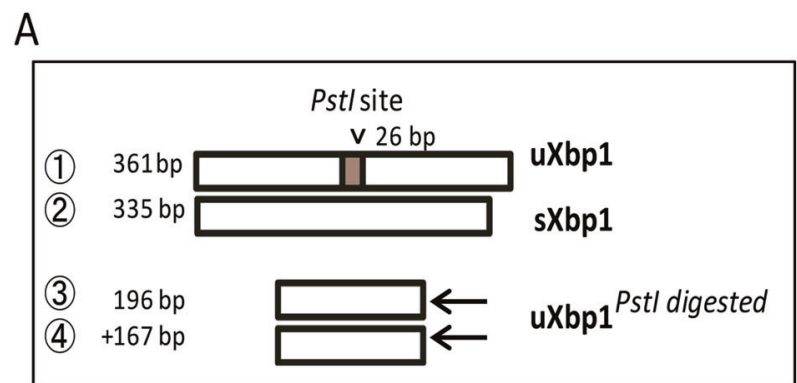

B
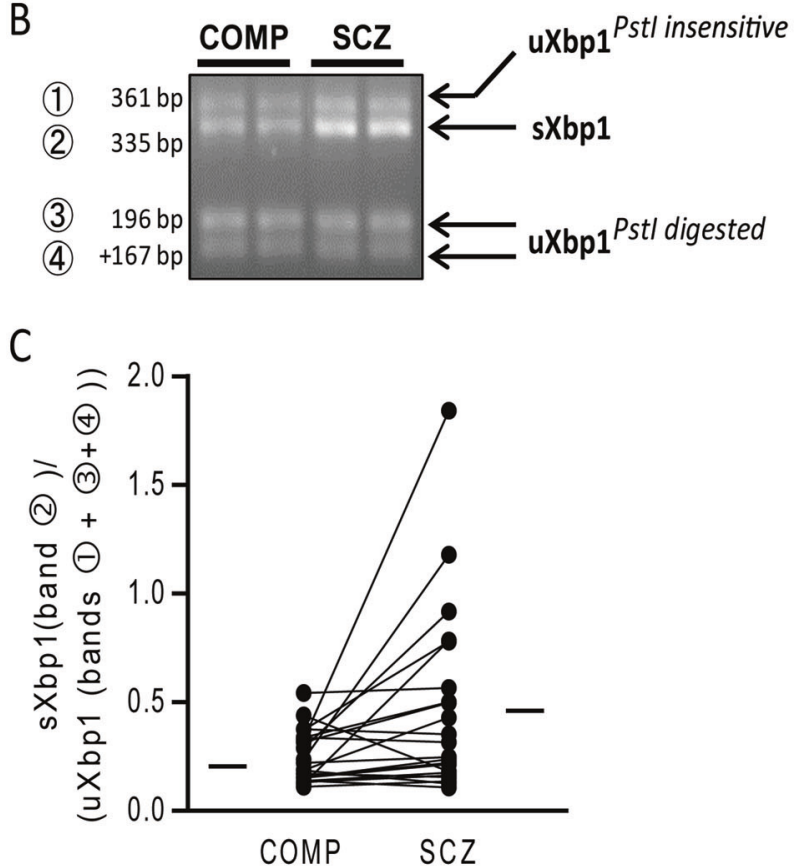

Fig. 4 Unconventional Xbp1 mRNA Splicing is changed in schizophrenia. a Diagram illustrating the predicted mRNA products of Xbp1 and their digestion by PstI. uXbp1 (band 1) contain a Pstl site that leads to cleavage into two transcripts (bands 3 and 4), although some of this population appears to be resistant to Pstl digestion. The unique PstI site is removed when Xbp1 is spliced by IRE1 $\alpha$ (sXbp1), resulting in this band (2) being unaffected by Pstl digestion. b Representative resultant mRNA digested with PstI follow by emulsion cDNA and PCR amplification, and analyzed by $2 \%$ agarose gel electrophoresis to visualize the spliced (s) and unspliced (u) products. c The ratio of sXbp1/ uXbp1 mRNA levels was increased in paired schizophrenia (SCZ) and comparison (COMP) subjects. Data are expressed as means \pm SEM. $* * p<0.01$

resulting in a translational frameshift and the sXBP1 production of the spliced form of Xbp1, sXBP1 acts as a transcription factor and promotes expression of the ER translocon, ER chaperones, proteins that facilitate ERAD, glycosylation enzymes, and phospholipids [6, 27, 28, 69]. Upregulation of these pathways increases resilience of the cell to ER stress, with chaperones and glycosylation enzymes facilitating increased demand for protein folding, ERAD components clearing misfolded proteins, and phospholipids allowing for the expansion of the ER membrane during ER stress [6, 27, 28, 69]. Despite observing decreased p-IRE1 $\alpha$ in SCZ, we observed upregulation of both sXbp1 mRNA and protein expression, suggesting upregulation of sXBP1-dependent processes. Supporting this, ERQC and ERAD components have been shown to be upregulated in the DLPFC in SCZ [46]. In addition, our lab has previously reported abnormal immature $N$-linked glycosylation, an ER-specific protein modification, of components of the glutamate and GABA systems in the frontal cortex in SCZ [40, 45, 74, 75]. Proper regulation of the IRE1- XBP1 pathway is particularly important for neural development [76, 77], and sXBP1 has been shown to specifically impact neurotransmitter systems in a developmental-dependent manner [29, 77]. In Xbp1-/ neurons, Hayashi et al. [77] observed inhibition of BDNFinduced expression of GABAergic markers. In C. elegans, mutants lacking either ire-1 or xbp-1 demonstrated development-dependent inhibition of glutamate receptor trafficking [29]. In SCZ, reduced expression of GABAergic markers has been repeatedly observed, and dysfunction in glutamatergic signaling is believed to be a key component of the illness [78, 79]. As a central regulator of the processes impacting these systems, sXBP1-dependent transcription may contribute to developmental deficits and neurotransmitter dysfunction.

The kinase and RNase activity of IRE1 $\alpha$ have been shown to be independently regulated, with certain conformations promoting high kinase activity, others promoting high RNase activity, and some resulting in a combination of the two [80]. A potential mechanism to explain the disconnect between downregulation of p-IRE1 $\alpha$ and upregulation of Xbpl splicing is a selective downregulation of high-kinase IRE1 $\alpha$ complexes and preservation of oligomeric complexes with low kinase activity and high RNase activity [80]. Alternatively, Hsp72 has been shown to bind to IRE1 $\alpha$ and specifically increase production of sXbp1 without increasing JNK2 phosphorylation [81]. This process appears to be cytoprotective [81]. These mechanisms are not mutually exclusive, and further work to define IRE $1 \alpha$ regulation is necessary to fully understand how IRE1 $\alpha$ dynamics are impacted in SCZ.

In addition to Xbp1 splicing, IRE1 $\alpha$ RNase activity also mediated regulated IRE1-dependent decay of mRNAs (RIDD), in which IRE1 $\alpha$ degrades ER-localized transcripts to decrease translation and therefore reduce demand for protein folding and quality processes in the face of cellular stress [82, 83]. Abnormal phosphorylation IRE1 $\alpha$ and Xbp1 splicing both suggest that this system is also likely dysregulated. While we are unable to directly demonstrate the impact of IRE1 $\alpha$ RNase activity on ER-associated transcripts in this study, this process may contribute to the disconnect between transcript and protein expression in SCZ postmortem brain $[84,85]$. In addition to dysregulation 
of the IRE1 $\alpha$ pathway, we also observed decreased PERK expression in SCZ. However, this expression was correlated with age and an ANCOVA indicated that, when controlling for age, the effect of diagnosis on PERK expression is no longer significant. This suggests that what we observed is an effect of aging on the UPR. Age-related neurological disorders have been associated with UPR dysfunction, suggesting that this system is particularly susceptible to stressors during the aging [30-34, 69, 86, 87]. In addition, PERK mRNA has been specifically shown to be reduced in the hippocampus of aged rats [88]. This suggests that the UPR, and the PERK pathway in particular, is sensitive to aging and likely underlies an altered capacity to deal with ER stress in elderly individuals.

This study has several limitations. While our subjects were well-matched, they were elderly and the pathophysiology of subjects who are at later stages of the illness may not reflect abnormalities associated with earlier stages of the disorder. Using postmortem tissue limited us to investigating the UPR pathway in a cross-sectional fashion. It has been previously shown that constitutive UPR activity regulates distinct pathways from ER-stress induced UPR activity [89]. Therefore, while we can conclude that markers of constitutive UPR activity are abnormally expressed, we can only speculate on whether these pathways might respond to cellular stress differently in SCZ. Studies detailing the effects of protein and phosphorylation abnormalities on both constitutive and stress-induced UPR activity would be necessary to elucidate the mechanisms by which these abnormalities are contribute to pathophysiology of SCZ. In addition, the majority of the subjects with SCZ were on antipsychotics for long periods of time. To address this confounding factor we measured the changes we observed in postmortem brain tissue in rats chronically treated with haloperidol, a commonly used first generation antipsychotic, and found no changes due to treatment. This suggests that antipsychotic treatment is not sufficient to induce these changes in brain, making our findings more likely to be due to the illness rather than chronic antipsychotic treatment.

In summary, we examined expression of key elements in the UPR in the DLPFC of patients with SCZ and matched comparison subjects. These findings suggest an abnormal pattern of constitutive UPR activity, with upregulation of cell-protective pathways and downregulation of factors known to promote apoptosis. These abnormalities may contribute to aberrant protein processing and trafficking, and dysfunctional response to cellular stress in SCZ.

\section{Compliance with ethical standards}

Conflict of interest The authors declare that they have no conflict of interest.
Publisher's note Springer Nature remains neutral with regard to jurisdictional claims in published maps and institutional affiliations.

\section{References}

1. Spear LP. Adolescent neurodevelopment. J Adolesc Health. 2013;52(2Suppl 2):S7-13.

2. Uhlhaas PJ, Singer W. The development of neural synchrony and large-scale cortical networks during adolescence: relevance for the pathophysiology of schizophrenia and neurodevelopmental hypothesis. Schizophr Bull. 2011;37:514-23.

3. Eggers AE. A serotonin hypothesis of schizophrenia. Med Hypotheses. 2013;80:791-4.

4. Laruelle M. Schizophrenia: from dopaminergic to glutamatergic interventions. Curr Opin Pharm. 2014;14:97-102.

5. Nakazawa K, Zsiros V, Jiang Z, Nakao K, Kolata S, Zhang S, et al. GABAergic interneuron origin of schizophrenia pathophysiology. Neuropharmacology. 2012;62:1574-83.

6. Hebert DN, Molinari M. In and out of the ER: protein folding, quality control, degradation, and related human diseases. Physiol Rev. 2007;87:1377-408.

7. Dufey E, Sepulveda D, Rojas-Rivera D, Hetz C. Cellular mechanisms of endoplasmic reticulum stress signaling in health and disease. 1. An overview. Am J Physiol Cell Physiol. 2014; 307:C582-594.

8. Pluquet $\mathrm{O}$, Pourtier A, Abbadie C. The unfolded protein response and cellular senescence. A review in the theme: cellular mechanisms of endoplasmic reticulum stress signaling in health and disease. Am J Physiol Cell Physiol. 2015;308:C415-425.

9. Lee AS, Delegeane A, Scharff D. Highly conserved glucoseregulated protein in hamster and chicken cells: preliminary characterization of its cDNA clone. Proc Natl Acad Sci USA. 1981;78:4922-5.

10. Rao RV, Peel A, Logvinova A, del Rio G, Hermel E, Yokota T, et al. Coupling endoplasmic reticulum stress to the cell death program: role of the ER chaperone GRP78. FEBS Lett. 2002;514:122-8.

11. Zhang Y, Liu R, Ni M, Gill P, Lee AS. Cell surface relocalization of the endoplasmic reticulum chaperone and unfolded protein response regulator GRP78/BiP. J Biol Chem. 2010;285:15065-75.

12. Zhang LH, Zhang X. Roles of GRP78 in physiology and cancer. J Cell Biochem. 2010;110:1299-305.

13. Malhotra JD, Kaufman RJ. The endoplasmic reticulum and the unfolded protein response. Semin Cell Dev Biol. 2007;18:716-31.

14. Schonthal AH. Targeting endoplasmic reticulum stress for cancer therapy. Front Biosci. 2012;4:412-31.

15. Healy SJ, Gorman AM, Mousavi-Shafaei P, Gupta S, Samali A. Targeting the endoplasmic reticulum-stress response as an anticancer strategy. Eur J Pharmacol. 2009;625:234-46.

16. Manie SN, Lebeau J, Chevet E. Cellular mechanisms of endoplasmic reticulum stress signaling in health and disease. 3 . Orchestrating the unfolded protein response in oncogenesis: an update. Am J Physiol Cell Physiol. 2014;307:C901-907.

17. Haze K, Yoshida H, Yanagi H, Yura T, Mori K. Mammalian transcription factor ATF6 is synthesized as a transmembrane protein and activated by proteolysis in response to endoplasmic reticulum stress. Mol Biol Cell. 1999;10:3787-99.

18. Okada T, Haze K, Nadanaka S, Yoshida H, Seidah NG, Hirano Y, et al. A serine protease inhibitor prevents endoplasmic reticulum stress-induced cleavage but not transport of the membrane-bound transcription factor ATF6. J Biol Chem. 2003;278:31024-32.

19. Shen J, Chen X, Hendershot L, Prywes R. ER stress regulation of ATF6 localization by dissociation of BiP/GRP78 binding and unmasking of Golgi localization signals. Dev Cell. 2002;3:99-111. 
20. Adachi Y, Yamamoto K, Okada T, Yoshida H, Harada A, Mori K. ATF6 is a transcription factor specializing in the regulation of quality control proteins in the endoplasmic reticulum. Cell Struct Funct. 2008;33:75-89.

21. Harding HP, Zhang Y, Bertolotti A, Zeng H, Ron D. Perk is essential for translational regulation and cell survival during the unfolded protein response. Mol Cell. 2000;5:897-904.

22. Munoz JP, Ivanova S, Sanchez-Wandelmer J, Martinez-Cristobal $\mathrm{P}$, Noguera E, Sancho A, et al. Mfn2 modulates the UPR and mitochondrial function via repression of PERK. EMBO J. 2013;32:2348-61.

23. Hetz C, Glimcher LH. Fine-tuning of the unfolded protein response: assembling the IRE1alpha interactome. Mol Cell. 2009; 35:551-61.

24. Imagawa Y, Hosoda A, Sasaka S, Tsuru A, Kohno K. RNase domains determine the functional difference between IRE1alpha and IRE1beta. FEBS Lett. 2008;582:656-60.

25. Braakman I, Bulleid NJ. Protein folding and modification in the mammalian endoplasmic reticulum. Annu Rev Biochem. 2011; 80:71-99.

26. Jager R, Bertrand MJ, Gorman AM, Vandenabeele P, Samali A. The unfolded protein response at the crossroads of cellular life and death during endoplasmic reticulum stress. Biol Cell. 2012;104:259-70.

27. Hetz C. The unfolded protein response: controlling cell fate decisions under ER stress and beyond. Nat Rev Mol Cell Biol. 2012;13:89-102.

28. Samali A, Fitzgerald U, Deegan S, Gupta S. Methods for monitoring endoplasmic reticulum stress and the unfolded protein response. Int J Cell Biol. 2010;2010:830307.

29. Shim J, Umemura T, Nothstein E, Rongo C. The unfolded protein response regulates glutamate receptor export from the endoplasmic reticulum. Mol Biol Cell. 2004;15:4818-28.

30. Hoozemans JJ, Veerhuis R, Van Haastert ES, Rozemuller JM, Baas $\mathrm{F}$, Eikelenboom $\mathrm{P}$, et al. The unfolded protein response is activated in Alzheimer's disease. Acta Neuropathol. 2005;110:165-72.

31. Ryu EJ, Harding HP, Angelastro JM, Vitolo OV, Ron D, Greene LA. Endoplasmic reticulum stress and the unfolded protein response in cellular models of Parkinson's disease. J Neurosci. 2002;22:10690-8.

32. Atkin JD, Farg MA, Walker AK, McLean C, Tomas D, Horne MK. Endoplasmic reticulum stress and induction of the unfolded protein response in human sporadic amyotrophic lateral sclerosis. Neurobiol Dis. 2008;30:400-7.

33. Duennwald ML, Lindquist S. Impaired ERAD and ER stress are early and specific events in polyglutamine toxicity. Genes Dev. 2008;22:3308-19.

34. Vidal RL, Figueroa A, Court FA, Thielen P, Molina C, Wirth C, et al. Targeting the UPR transcription factor XBP1 protects against Huntington's disease through the regulation of FoxO1 and autophagy. Hum Mol Genet. 2012;21:2245-62.

35. Hetz C, Russelakis-Carneiro M, Maundrell K, Castilla J, Soto C. Caspase-12 and endoplasmic reticulum stress mediate neurotoxicity of pathological prion protein. EMBO J. 2003;22:5435-45.

36. Gold PW, Licinio J, Pavlatou MG. Pathological parainflammation and endoplasmic reticulum stress in depression: potential translational targets through the CNS insulin, klotho and PPAR-gamma systems. Mol Psychiatry. 2013;18:154-65.

37. Nevell L, Zhang K, Aiello AE, Koenen K, Galea S, Soliven R, et al. Elevated systemic expression of ER stress related genes is associated with stress-related mental disorders in the Detroit Neighborhood Health Study. Psychoneuroendocrinology. 2014;43:62-70.

38. So J, Warsh JJ, Li PP. Impaired endoplasmic reticulum stress response in B-lymphoblasts from patients with bipolar-I disorder. Biol Psychiatry. 2007;62:141-7.

39. Hunsberger JG, Machado-Vieira R, Austin DR, Zarate C, Chuang DM, Chen G, et al. Bax inhibitor 1, a modulator of calcium homeostasis, confers affective resilience. Brain Res. 2011;1403:19-27.

40. Bauer D, Haroutunian V, Meador-Woodruff JH, McCullumsmith RE. Abnormal glycosylation of EAAT1 and EAAT2 in prefrontal cortex of elderly patients with schizophrenia. Schizophr Res. 2010;117:92-98.

41. Funk AJ, Rumbaugh G, Harotunian V, McCullumsmith RE, Meador-Woodruff JH. Decreased expression of NMDA receptorassociated proteins in frontal cortex of elderly patients with schizophrenia. Neuroreport. 2009;20:1019-22.

42. Hammond JC, McCullumsmith RE, Funk AJ, Haroutunian V, Meador-Woodruff JH. Evidence for abnormal forward trafficking of AMPA receptors in frontal cortex of elderly patients with schizophrenia. Neuropsychopharmacology. 2010;35:2110-9.

43. Kristiansen LV, Patel SA, Haroutunian V, Meador-Woodruff JH. Expression of the NR2B-NMDA receptor subunit and its Tbr-1/ CINAP regulatory proteins in postmortem brain suggest altered receptor processing in schizophrenia. Synapse. 2010;64:495-502.

44. Kristiansen LV, Bakir B, Haroutunian V, Meador-Woodruff JH. Expression of the NR2B-NMDA receptor trafficking complex in prefrontal cortex from a group of elderly patients with schizophrenia. Schizophr Res. 2010;119:198-209.

45. Mueller TM, Haroutunian V, Meador-Woodruff JH. $\mathrm{N}$-Glycosylation of GABAA receptor subunits is altered in Schizophrenia. Neuropsychopharmacology. 2014;39:528-37.

46. Kim P, Scott MR, Meador-Woodruff JH. Abnormal expression of ER quality control and ER associated degradation proteins in the dorsolateral prefrontal cortex in schizophrenia. Schizophr Res. 2018;197:484-91.

47. Kim P, Scott MR, Meador-Woodruff JH. Abnormal ER quality control of neural GPI-anchored proteins via dysfunction in ER export processing in the frontal cortex of elderly subjects with schizophrenia. Transl Psychiatry. 2019;9:6.

48. Powchik P, Davidson M, Haroutunian V, Gabriel SM, Purohit DP, Perl DP, et al. Postmortem studies in schizophrenia. Schizophr Bull. 1998;24:325-41.

49. Purohit DP, Perl DP, Haroutunian V, Powchik P, Davidson M, Davis KL. Alzheimer disease and related neurodegenerative diseases in elderly patients with schizophrenia: a postmortem neuropathologic study of 100 cases. Arch Gen Psychiatry. 1998;55:205-11.

50. Harte MK, Bachus SB, Reynolds GP. Increased N-acetylaspartate in rat striatum following long-term administration of haloperidol. Schizophr Res. 2005;75:303-8.

51. Kashihara K, Sato M, Fujiwara Y, Ogawa T, Fukuda K, Otsuki S. Effects of intermittent and continuous haloperidol administration on the dopaminergic system in the rat brain. Yakubutsu Seishin Kodo. 1986;6:275-80.

52. Kippe JM, Mueller TM, Haroutunian V, Meador-Woodruff JH. Abnormal $\mathrm{N}$-acetylglucosaminyltransferase expression in prefrontal cortex in schizophrenia. Schizophr Res. 2015;166:219-24.

53. White K, Yang P, Li L, Farshori A, Medina AE, Zielke HR. Effect of postmortem interval and years in storage on RNA quality of tissue at a repository of the NIH NeuroBioBank. Biopreserv Biobank. 2018;16:148-57.

54. Stan AD, Ghose S, Gao XM, Roberts RC, Lewis-Amezcua K, Hatanpaa KJ, et al. Human postmortem tissue: what quality markers matter? Brain Res. 2006;1123:1-11.

55. Chalmers F, van Lith M, Sweeney B, Cain K, Bulleid NJ. Inhibition of IRE1alpha-mediated XBP1 mRNA cleavage by XBP1 reveals a novel regulatory process during the unfolded protein response. Wellcome Open Res. 2017;2:36.

56. Yamamoto K, Yoshida H, Kokame K, Kaufman RJ, Mori K. Differential contributions of ATF6 and XBP1 to the activation of endoplasmic reticulum stress-responsive cis-acting elements ERSE, UPRE and ERSE-II. J Biochem. 2004;136:343-50. 
57. McGuckin MA, Eri RD, Das I, Lourie R, Florin TH. ER stress and the unfolded protein response in intestinal inflammation. Am $\mathbf{J}$ Physiol Gastrointest Liver Physiol. 2010;298:G820-832.

58. Focking M, Lopez LM, English JA, Dicker P, Wolff A, Brindley E, et al. Proteomic and genomic evidence implicates the postsynaptic density in schizophrenia. Mol Psychiatry. 2015;20:424-32.

59. Martins-de-Souza D, Gattaz WF, Schmitt A, Rewerts C, Maccarrone G, Dias-Neto E, et al. Prefrontal cortex shotgun proteome analysis reveals altered calcium homeostasis and immune system imbalance in schizophrenia. Eur Arch Psychiatry Clin Neurosci. 2009;259:151-63.

60. Martins-de-Souza D, Gattaz WF, Schmitt A, Maccarrone G, Hunyadi-Gulyas E, Eberlin MN, et al. Proteomic analysis of dorsolateral prefrontal cortex indicates the involvement of cytoskeleton, oligodendrocyte, energy metabolism and new potential markers in schizophrenia. J Psychiatr Res. 2009;43:978-86.

61. Sivagnanasundaram S, Crossett B, Dedova I, Cordwell S, Matsumoto I. Abnormal pathways in the genu of the corpus callosum in schizophrenia pathogenesis: a proteome study. Proteom Clin Appl. 2007;1:1291-305.

62. Dudek J, Benedix J, Cappel S, Greiner M, Jalal C, Muller L, et al. Functions and pathologies of $\mathrm{BiP}$ and its interaction partners. Cell Mol life Sci. 2009;66:1556-69.

63. Luo B, Lee AS. The critical roles of endoplasmic reticulum chaperones and unfolded protein response in tumorigenesis and anticancer therapies. Oncogene. 2013;32:805-18.

64. Boskovic M, Vovk T, Kores Plesnicar B, Grabnar I. Oxidative stress in schizophrenia. Curr Neuropharmacol. 2011;9:301-12.

65. Gonzalez-Liencres C, Tas C, Brown EC, Erdin S, Onur E, Cubukcoglu Z, et al. Oxidative stress in schizophrenia: a casecontrol study on the effects on social cognition and neurocognition. BMC Psychiatry. 2014;14:268.

66. Rajasekaran A, Venkatasubramanian G, Berk M, Debnath M. Mitochondrial dysfunction in schizophrenia: pathways, mechanisms and implications. Neurosci Biobehav Rev. 2015;48:10-21.

67. Reyazuddin M, Azmi SA, Islam N, Rizvi A. Oxidative stress and level of antioxidant enzymes in drug-naive schizophrenics. Indian J Psychiatry. 2014;56:344-9.

68. Patil C, Walter P. Intracellular signaling from the endoplasmic reticulum to the nucleus: the unfolded protein response in yeast and mammals. Curr Opin Cell Biol. 2001;13:349-55.

69. Hetz C, Chevet E, Harding HP. Targeting the unfolded protein response in disease. Nat Rev Drug Discov. 2013;12:703-19.

70. Kato H, Nakajima S, Saito Y, Takahashi S, Katoh R, Kitamura M. mTORC1 serves ER stress-triggered apoptosis via selective activation of the IRE1-JNK pathway. Cell Death Differ. 2012;19:310-20.

71. Akbarian S, Kim JJ, Potkin SG, Hagman JO, Tafazzoli A, Bunney WE, et al. Gene expression for glutamic acid decarboxylase is reduced without loss of neurons in prefrontal cortex of schizophrenics. Arch Gen Psychiatry. 1995;52:258-66.

72. Glantz LA, Gilmore JH, Lieberman JA, Jarskog LF. Apoptotic mechanisms and the synaptic pathology of schizophrenia. Schizophr Res. 2006;81:47-63.

73. Funk AJ, McCullumsmith RE, Haroutunian V, Meador-Woodruff JH. Abnormal activity of the MAPK- and cAMP-associated signaling pathways in frontal cortical areas in postmortem brain in schizophrenia. Neuropsychopharmacology. 2012;37:896-905.
74. Tucholski J, Simmons MS, Pinner AL, McMillan LD, Haroutunian V, Meador-Woodruff JH. N-linked glycosylation of cortical N-methyl-D-aspartate and kainate receptor subunits in schizophrenia. Neuroreport. 2013;24:688-91.

75. Tucholski J, Simmons MS, Pinner AL, Haroutunian V, McCullumsmith RE, Meador-Woodruff JH. Abnormal N-linked glycosylation of cortical AMPA receptor subunits in schizophrenia. Schizophr Res. 2013;146:177-83.

76. Hayashi A, Kasahara T, Iwamoto K, Ishiwata M, Kametani M, Kakiuchi $\mathrm{C}$, et al. The role of brain-derived neurotrophic factor (BDNF)-induced XBP1 splicing during brain development. J Biol Chem. 2007;282:34525-34.

77. Hayashi A, Kasahara T, Kametani M, Kato T. Attenuated BDNFinduced upregulation of GABAergic markers in neurons lacking Xbp1. Biochem Biophys Res Commun. 2008;376:758-63.

78. Hashimoto T, Arion D, Unger T, Maldonado-Aviles JG, Morris HM, Volk DW, et al. Alterations in GABA-related transcriptome in the dorsolateral prefrontal cortex of subjects with schizophrenia. Mol Psychiatry. 2008;13:147-61.

79. Gonzalez-Burgos G, Fish KN, Lewis DA. GABA neuron alterations, cortical circuit dysfunction and cognitive deficits in schizophrenia. Neural Plast. 2011;2011:723184.

80. Joshi S, Rajasekaran K, Hawk KM, Brar J, Ross BM, Tran CA, et al. Phosphatase inhibition prevents the activity-dependent trafficking of GABAA receptors during status epilepticus in the young animal. Epilepsia. 2015;56:1355-65.

81. Gupta S, Deepti A, Deegan S, Lisbona F, Hetz C, Samali A. HSP72 protects cells from ER stress-induced apoptosis via enhancement of IRE1alpha-XBP1 signaling through a physical interaction. PLoS Biol. 2010;8:e1000410.

82. Hollien J, Weissman JS. Decay of endoplasmic reticulumlocalized mRNAs during the unfolded protein response. Science. 2006;313:104-7.

83. Harnsberger JD, Hollien H, Martin CA, Hollien KA. Stress and deception in speech: evaluating layered voice analysis. J For Sci. 2009;54:642-50.

84. Bauernfeind AL, Soderblom EJ, Turner ME, Moseley MA, Ely JJ, Hof PR, et al. Evolutionary divergence of gene and protein expression in the brains of humans and chimpanzees. Genome Biol Evol. 2015;7:2276-88.

85. Vogel C, Marcotte EM. Insights into the regulation of protein abundance from proteomic and transcriptomic analyses. Nat Rev Genet. 2012;13:227-32.

86. Carnemolla A, Fossale E, Agostoni E, Michelazzi S, Calligaris R, De Maso L, et al. Rrs1 is involved in endoplasmic reticulum stress response in Huntington disease. J Biol Chem. 2009;284:18167-73.

87. Hoozemans JJ, van Haastert ES, Eikelenboom P, de Vos RA, Rozemuller JM, Scheper W. Activation of the unfolded protein response in Parkinson's disease. Biochem Biophys Res Commun. 2007;354:707-11.

88. Paz Gavilan M, Vela J, Castano A, Ramos B, del Rio JC, Vitorica $\mathrm{J}$, et al. Cellular environment facilitates protein accumulation in aged rat hippocampus. Neurobiol Aging. 2006;27:973-82.

89. Shen X, Ellis RE, Sakaki K, Kaufman RJ. Genetic interactions due to constitutive and inducible gene regulation mediated by the unfolded protein response in C. elegans. PLoS Genet. 2005;1:e37. 